\title{
Biotic resistance and facilitation of a non-native oyster on rocky shores
}

\author{
Jennifer L. Ruesink* \\ Department of Zoology, University of British Columbia, Vancouver, British Columbia V6T 1Z4, Canada \\ Present address: Department of Biology, University of Washington, Box 351800, Seattle, Washington 98195-1800, USA
}

\begin{abstract}
The Pacific oyster Crassostrea gigas varies dramatically in density throughout its introduced range in the northeast Pacific; this could be driven by environmental constraints or by species interactions that change across habitats. I studied the effects of native species on this invader across a range of environmental contexts where it is common (mid-intertidal zone, low wave exposure) vs. where it is rare (low intertidal zone, high wave exposure) in Barkley Sound, Vancouver Island, Canada. I carried out factorial manipulations of 2 guilds of native species (neighbors, i.e. filter feeders such as mussels and barnacles, and predators such as crabs and whelks) and recorded survival and linear shell growth of transplanted, newly settled oysters (juveniles $\sim 1 \mathrm{~cm}$ in size). C. gigas responded dramatically to tidal elevation: growth improved but survival declined at lower elevations, where feeding time and predation were greater. Wave exposure reduced shell growth over 2 mo from $11.4 \mathrm{~mm}$ at protected sites to $7.2 \mathrm{~mm}$ at exposed sites, but variation in survival was not statistically significant. Both guilds of native species exerted biotic resistance: predators reduced oyster survival and neighbors reduced growth. Surprisingly, neighbors improved oyster survival at some waveexposed sites, thereby facilitating one demographic variable related to invasion while restricting another. Finally, predation had equivalent effects on survival at waveexposed and protected sites, although different predators were probably involved. Post-recruitment phenomena were unable to account for variation in oyster density across sites, and propagule pressure is a likely driver instead. Abiotic and biotic factors jointly contributed to the risk of proliferation of a non-native species, and in this case their influence was often (on growth) but not always (on survival) additive.
\end{abstract}

KEYWORDS: Invasion - Non-indigenous species · Competition · Predation · Survival · Intertidal · Pacific oyster $\cdot$ Crassostrea gigas

Resale or republication not permitted without written consent of the publisher

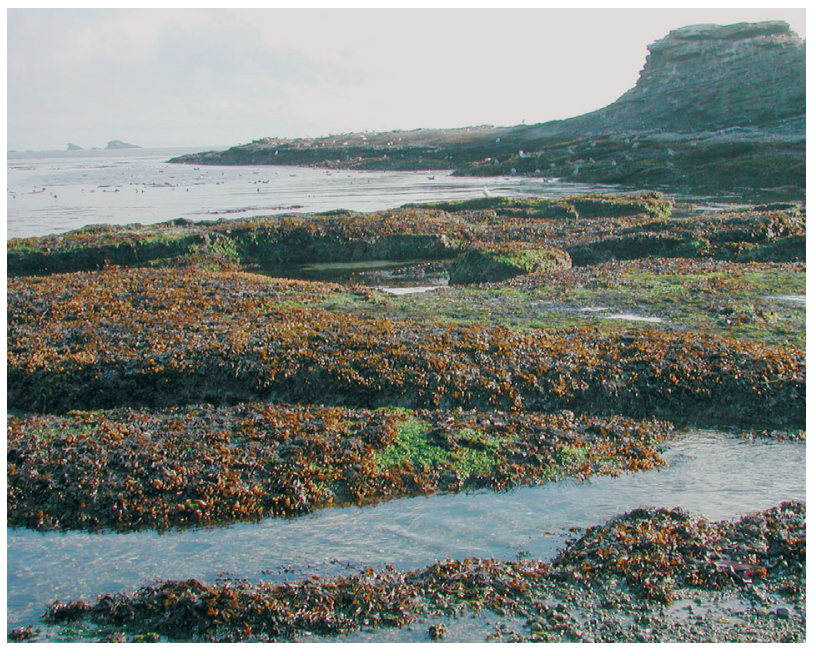

According to invasion theory, species interactions-notably competition and predation - should prevent the proliferation of exotics on rocky shorelines. In a field experiment in western Canada, however, both biotic resistance and facilitation occurred. Introduced Pacific oysters Crassostrea gigas were eaten by native predators, but native neighbors conferred protection to the alien species.

Photo: Alan Trimble

\section{INTRODUCTION}

As the effects of non-indigenous species increase in magnitude and recognition (OTA 1993, Pimentel et al. 2000), a key challenge is to understand the ecological mechanisms that keep some invaders locally rare in their introduced range. Invaders at low abundance are unlikely to cause community or ecosystem level change (Parker et al. 1999), except for the local increase of species richness. Therefore, predicting and augmenting natural resistance to invasion (establishment or proliferation) will aid in reducing overall im- 
pacts of introduced species. Invaders that vary spatially in abundance are particularly instructive for testing mechanisms of invasion resistance, because although such species are capable of dominating assemblages, they are not capable of doing so in all contexts. The Pacific oyster, Crassostrea gigas, has established populations along shorelines of the northeast Pacific Ocean after its repeated introduction for aquaculture since the early 1900s (Bourne 1979). The larvae of $C$. gigas spend 2 to 4 wk in the plankton where they disperse widely (Quayle 1964). Adults are found primarily in wave-protected habitats and can dominate intertidal areas as a consequence of high numbers and large size (up to $30 \mathrm{~cm}$ ). However, in most locations along the coast, oysters are rare, suggesting some mechanisms of resistance to invasion or proliferation.

Hypotheses about invasion limits fall broadly into 2 categories. (1) Autecological hypotheses focus on suitable environmental conditions, such as temperature and moisture (Peterson \& Vieglais 2001). (2) Biotic resistance proposes that species interactions set invasion limits. For several decades, invasion biologists have suggested that species-rich assemblages should exclude invaders or limit their effects (Elton 1958, Rejmanek 1989, Chapin et al. 1998). This biotic resistance could arise because many ecological roles are already filled, so that a new species experiences strong competition and predation (Crawley 1986, Lodge 1993, Mack 1996, Shea \& Chesson 2002), or because resources are diverse and difficult to monopolize (Burdon 1987).

Native species have rarely been observed to exclude non-natives entirely, but they can prevent proliferation (Levine et al. 2004, Bishop \& Peterson 2006). Examples of this include aquatic predators reducing an invader's survival (Robinson \& Wellborn 1988, Reusch 1998, Bishop \& Peterson 2006) or competitors disproportionately occupying space (Jensen et al. 2002), native plants outperforming or restricting invaders under some environmental conditions (Levine 2000, Goergen \& Daehler 2001), and certain combinations of protists preventing an additional species from establishing in microcosms (Law et al. 2000). To date, few of these studies have examined interactive effects of multiple species and trophic levels (e.g. just 6 of 24 plant ecology studies analyzed by Levine et al. 2004).

In this study, I examined abiotic and biotic factors that could limit the proliferation of Pacific oyster Crassostrea gigas on the northeast Pacific coast, focusing on a region of dramatic spatial variation in abundance. The goal was to explore factors keeping the invader locally rare, especially the effects of 2 trophic guilds of native species across ranges of wave exposure and tidal elevation. Specifically, I asked the following:

(1) What are the relative contributions of abiotic and biotic factors in determining the distribution of nonnative oysters on a rocky shoreline?

(2) What are the interactive effects of 2 native guilds (potential predators and competitors) on non-native oyster demography?

\section{MATERIALS AND METHODS}

Study sites and native species. Six rocky intertidal sites were studied, distributed across $10 \mathrm{~km}$ of Barkley Sound on the west coast of Vancouver Island, British Columbia, Canada $\left(48^{\circ} 57^{\prime} \mathrm{N}, 125^{\circ} 15^{\prime} \mathrm{W}\right)$. One waveexposed site and 1 wave-protected site were chosen in each of the Pinkerton Islands, south Alma Russell Island (near Mahk Rock), and north Alma Russell Island (Kyen Point). The 3 wave-exposed sites fronted an exposed fetch of at least $6 \mathrm{~km}$. Dissolution blocks at these sites disappeared more than twice as fast as at wave-protected sites (Table 1), where the fetch did not

Table 1. Description of 6 sites where oysters were transplanted. Data are mean (SE), sample size (N), of $0.25 \mathrm{~m}^{2}$ quadrats $\left(1 \mathrm{~m}^{2}\right.$ for seastars) at 1 to $2.5 \mathrm{~m}$ above lowest normal tide (LNT) at each site. Percentage data are back-transformed from arcsine square root-transformed values, so SEs are asymmetric and presented as lower and upper bounds (lower; upper). (+) present at site but not recorded in quantitative samples. Oysters: Crassostrea gigas; mussels: Mytilus californianus; seastars: Pisaster ochraceus; whelks: Nucella spp.

\begin{tabular}{|c|c|c|c|c|c|c|c|}
\hline & $\begin{array}{c}\text { Dissolution } \\
\text { block loss } \\
(\%)\end{array}$ & $\begin{array}{l}\text { Bare rock } \\
\text { cover } \\
(\%)\end{array}$ & $\begin{array}{l}\text { Mussel bed } \\
\text { cover } \\
(\%)\end{array}$ & $\begin{array}{c}\text { Oyster } \\
\text { density } \\
\left(\mathrm{m}^{-2}\right)\end{array}$ & $\begin{array}{l}\text { Oyster } \\
\text { cover } \\
(\%)\end{array}$ & $\begin{array}{l}\text { Seastar } \\
\text { density } \\
\left(\mathrm{m}^{-2}\right)\end{array}$ & $\begin{array}{l}\text { Whelk } \\
\text { density } \\
\left(\mathrm{m}^{-2}\right)\end{array}$ \\
\hline \multicolumn{8}{|c|}{ Wave-exposed } \\
\hline Kyen & $54(48 ; 60)$ & + & $85(71 ; 94)$ & + & + & $2.5( \pm 0.7)$ & $6.2( \pm 2.9)$ \\
\hline Mahk & $51(45 ; 56)$ & + & $73(55 ; 88)$ & + & + & $3.3( \pm 0.8)$ & $4.0( \pm 1.6)$ \\
\hline Pinkerton & $35(29 ; 42)$ & + & $53(28 ; 77)$ & + & + & $6.5( \pm 3.8)$ & $0.4( \pm 0.24)$ \\
\hline \multicolumn{8}{|c|}{ Wave-protected } \\
\hline Kyen & $20(18 ; 22)$ & $45(25 ; 65)$ & 0 & $10.0( \pm 2.4)$ & $3(0 ; 7)$ & + & 0 \\
\hline Mahk & $20(19 ; 21)$ & $63(51 ; 76)$ & 0 & $52.8( \pm 8.8)$ & $6(2 ; 11)$ & + & 0 \\
\hline Pinkerton & $15(14 ; 16)$ & $47(36 ; 57)$ & 0 & $34.4( \pm 2.7)$ & $6(1 ; 16)$ & + & + \\
\hline $\mathbf{N}$ & 4 & 5 & 5 & 10 & 5 & 5 & 5 \\
\hline
\end{tabular}


exceed $300 \mathrm{~m}$. Based on point samples (1 sample per week at low tide), water temperatures did not differ among sites and were sufficiently warm to allow larval development of oysters $\left(>15^{\circ} \mathrm{C}\right.$ from June to September; e.g. His et al. 1989).

In addition to their wave exposure differences, study sites also harbored different assemblages (Table 1). Wave-exposed sites showed little bare rock and contained extensive mussel beds (Mytilus californianus). Slow-moving benthic predators were relatively abundant. Although Crassostrea gigas was present, it did not appear in quantitative samples.

In contrast, about $50 \%$ cover of rock was unoccupied at wave-protected sites. Mytilus californianus did not occur there, and native space occupants included mostly barnacles and a fucoid algal canopy. Predators such as seastars and whelks were rare, but my sampling protocol did not effectively count crabs (Cancer spp.), which I regularly saw underwater at wave-protected sites. These sites contained more oysters than did exposed sites, although always $<10 \%$ cover (Table 1 ).

Experimental design, removal of native guilds. I manipulated 2 guilds of native species to test for biotic effects on post-recruitment demography of Crassostrea gigas: neighbors $(+/-\mathrm{N})$ and predators (+/- P). Neighbors were removed $(-\mathrm{N})$ by dislodging all organisms within $20 \mathrm{~cm}$ of transplanted oysters at wave-exposed sites. Species included potential competitors for space and food (mussels, Mytilus californianus; barnacles, Pollicipes polymerus and Semibalanus cariosus; anemones, Anthopleura elegantissima), as well as mobile filter feeders (porcelain crabs; Petrolisthes spp.). In treatments with neighbors present $(+N)$, a few mussels were removed in order to place oysters in mussel beds, but 'leaning' by mussels covered transplants within 2 weeks. Predators were reduced $(-\mathrm{P})$ by anchoring wire cages $(34 \times 23 \times 9 \mathrm{~cm}$ with $1 \mathrm{~cm}$ mesh on sides and $3.5 \mathrm{~cm}$ mesh on top) over transplanted oysters. Such large-mesh cages have been shown to have no 'cage effects' on growth or survival of filter-feeders (Wootton 1994), but they also required biweekly manual removal of predators that were not deterred by the mesh, especially small seastars and whelks.

At the 3 wave-exposed sites, predators and neighbors were manipulated in $2 \times 2$ factorial experiments to yield 4 treatments $(+\mathrm{N}+\mathrm{P},-\mathrm{N}+\mathrm{P},+\mathrm{N}-\mathrm{P}$, and $-\mathrm{N}-\mathrm{P})$. I set up a blocked design, in which each treatment was represented in each block, and blocks were placed throughout the mussel or oyster zone (1 to $2.5 \mathrm{~m}$ above lowest normal tide [LNT]) on available uniform surfaces. Tidal elevation of each block was estimated by comparing the time of immersion on at least 3 occasions to local tide predictions. Because of the high amount of bare space already available at waveprotected sites (Table 1), I did not examine neighbor effects there. All macroscopic organisms were scraped away from both treatments $(+\mathrm{P},-\mathrm{P})$ at these sites.

Newly-settled oysters were transplanted into each replicate 4 times (May 1997, July 1997, May 1998, July 1998), and their growth and survival tracked over 2 mo. These oysters (purchased from a commercial hatchery) were attached to single adult shells (called cultch). For each replicate, one cultch was anchored to the rock surface with a stainless steel screw. All oysters on cultch were initially mapped and measured (maximum shell length, to the nearest $0.5 \mathrm{~mm}$ ), and survivors were remeasured after 2 mo. Initial conditions in the 4 experiments were similar in oyster size (average shell lengths of 10.6, 8.7, 7.0, $5.6 \mathrm{~mm}$ ) and number per cultch (average initial counts of $16,10,10,11)$. Each cultch provided one replicate: survival was based on the proportion of initial oysters that survived to the end of the experiment, and growth was based on linear shell extension, averaged across all survivors. Each experiment lasted 2 mo, except in spring 1997 when experimental durations varied among the Pinkerton Islands (10 wk), Mahk Rock (6 wk), and Kyen Point (4 wk).

Data analysis. Growth and survival were analyzed as a function of 2 abiotic variables (wave exposure, tidal elevation) and 2 biotic variables (predators, neighbors) by analysis of covariance (ANCOVA) with separate slopes for the covariate, tidal elevation. Proportion surviving was $\ln (x+0.05)$-transformed prior to analysis to test appropriately for interactions among factors (Soluk 1993), so the dependent variable was the exponential rate of decline in numbers. ANCOVA requires that several factors acting independently have additive effects on a dependent variable: biologically, joint effects on survival are inherently multiplicative, not additive (i.e. mortality cannot exceed $100 \%$ ), but joint effects on the exponential rate of decline are expected to be additive. Results from spring 1997 were adjusted to 2 mo values for analysis, rather than using observed shell growth and population decline, which were measured over different time periods.

Results from the 4 experiments ( 2 seasons in 2 yr) were averaged, because oysters were anchored in identical locations each time, and temporal variation in post-recruitment performance was not of primary interest in this study. Furthermore, even after averaging across this repeated measure, analyses remained complicated and involved numerous potential interactive effects. ANCOVAs were set up to address a splitplot design, in which wave exposure varied at the plot (site) level, and 2 factors (predators, neighbors) varied at the subplot (block) level. Thus, sites were nested within wave exposure; I did not analyze wave-protected and exposed sites as pairs because the sites were selected for interspersion, not for similarity (see also Table 1). Rather than nesting blocks within sites, I in- 
stead included tidal elevation as a continuous factor, because all treatments in each block occurred at the same elevation. Neighbors were manipulated only where other space occupants occurred at high cover, so their effects were analyzed only at wave-exposed sites. A separate analysis for effects of wave-exposure, based on treatments without neighbors only, was performed for all sites.

Experiments at wave-exposed sites were analyzed as 4-way ANCOVAs with predators and neighbors included as fixed factors; site was considered a random factor and tidal elevation was a covariate. This analysis addressed the main and interactive effects of 2 native guilds on the invader across the abiotic gradient of tidal elevation. To test for effects of predators in the absence of neighbors, data from wave-exposed and waveprotected sites were evaluated as 4-way ANCOVAs with wave exposure and predators as fixed factors, and elevation as a covariate. Sites were nested within wave exposure as a random factor. Residuals were tested for homogeneity of variance by Levene's test, and data had homogeneous variances after one outlier in growth was removed (particularly slow growth, with poor survival, observed in one replicate at Pinkerton).

I calculated least-square means to compare magnitudes of effects. These differ from simple averages because of the covariate (tidal elevation): least-square means are calculated for a common tidal elevation despite the fact that blocks were set up at different elevations at each site. For purposes of displaying data, I back-transformed exponential mortality rates to percent survival over 2 mo.

\section{RESULTS}

\section{Abiotic and biotic effects on oyster growth}

Crassostrea gigas showed clear differences in growth with tidal elevation and neighbors, but no interactive effects; that is, predator and neighbor treatments did not have different effects across tidal elevation and wave exposure (where only predation was tested). ANCOVA results were similar for the 2 analyses: treatments without neighbors (Table 2), and wave-exposed only (Table 3). Elevation had significant main effects on growth, with growth slowing an average of $7.6 \mathrm{~mm}$ per $2 \mathrm{mo}$ (without neighbors across all sites) for each $1 \mathrm{~m}$ increase in tidal elevation (Fig. 1A). Oysters are not expected to grow above $2.6 \mathrm{~m}$ LNT. At wave-exposed sites, where neighbors were manipulated, shell growth improved from 3.2 to $5.8 \mathrm{~mm}$ per $2 \mathrm{mo}$ when neighbors were removed (Table 3, Fig. 1A,B). Wave exposure itself had a marginally significant effect on growth $(p=0.08$; Table 2 , Fig. 1A): without neighbors, oysters grew $11.4 \mathrm{~mm}$ over
Table 2. Crassostrea gigas. ANCOVA for oyster growth rate (linear shell extension) and oyster survival $(\ln (x+0.05)$ transformed proportion surviving), considering only treatments without neighbors. Elevation (covariate, allowed to interact with other factors), wave exposure (plot-level factor), and predators (subplot-level factor) were fixed factors. Sites were nested within wave exposure as a random factor, so $F$-ratio for wave exposure calculated accordingly. ${ }^{*} \mathrm{p}<0.05$, ${ }^{* *} \mathrm{p}<0.01,{ }^{* * *} \mathrm{p}<0.001$; superscript number: $0.05<\mathrm{p}<0.1$. Growth analyses were based on 35 residual df due to removal of one outlier. SS: sum of squares

\begin{tabular}{|c|c|c|c|c|c|}
\hline & \multirow[t]{2}{*}{ df } & \multicolumn{2}{|c|}{ Growth } & \multicolumn{2}{|c|}{ Survival } \\
\hline & & SS & $F$ & SS & $F$ \\
\hline Waves (W) & 1 & 127.1 & $5.89^{0.07}$ & 3.68 & 2.26 \\
\hline Site[Waves] (S[W]) & ) 4 & 93.1 & $5.91^{* *}$ & 7.13 & $14.62^{* * *}$ \\
\hline Elevation (E) & 1 & 283.9 & $72.09^{* * *}$ & 0.79 & $6.51^{*}$ \\
\hline Predators (P) & 1 & 4.56 & 1.16 & 2.18 & $17.87^{* * *}$ \\
\hline $\mathrm{W} \times \mathrm{E}$ & 1 & 6.67 & 1.69 & 0.17 & 1.37 \\
\hline $\mathrm{W} \times \mathrm{P}$ & 1 & 1.97 & 0.50 & 0.06 & 0.53 \\
\hline $\mathrm{S}[\mathrm{W}] \times \mathrm{E}$ & 4 & 10.2 & 0.65 & 2.38 & $4.89^{* *}$ \\
\hline $\mathrm{S}[\mathrm{W}] \times \mathrm{P}$ & 4 & 2.87 & 0.18 & 1.47 & $3.01^{*}$ \\
\hline$E \times P$ & 1 & 2.32 & 0.59 & 0.18 & 1.45 \\
\hline $\mathrm{W} \times \mathrm{E} \times \mathrm{P}$ & 1 & 1.14 & 0.29 & 0.17 & 1.44 \\
\hline $\mathrm{S}[\mathrm{W}] \times \mathrm{E} \times \mathrm{P}$ & 4 & 18.3 & 1.16 & 2.22 & $4.56^{* *}$ \\
\hline Residual & 35,36 & 137.8 & & 4.39 & \\
\hline
\end{tabular}

Table 3. Crassostrea gigas. ANCOVA for oyster growth rate (linear shell extension) and oyster survival $(\ln (x+0.05)$-transformed proportion surviving), considering only treatments at wave-exposed sites. Elevation (covariate, allowed to interact with other factors; separate slopes), predators and neighbors (subplot-level factors) were fixed factors. Sites were considered as a random factor. ${ }^{*} \mathrm{p}<0.05,{ }^{* *} \mathrm{p}<0.01,{ }^{* * *} \mathrm{p}<0.001$; superscript numbers: $0.05<p<0.1$. Growth analyses were based on 35 residual df due to removal of one outlier. SS: sum of squares

\begin{tabular}{|lccccc|}
\hline & df & \multicolumn{2}{c}{ Growth } & \multicolumn{2}{c|}{ Survival } \\
& & SS & $F$ & SS & $F$ \\
\hline Site (S) & 2 & 39.8 & $8.20^{* *}$ & 4.45 & $19.47^{* * *}$ \\
Elevation (E) & 1 & 143.1 & $58.86^{* * *}$ & 0.75 & $6.55^{*}$ \\
Predators (P) & 1 & 1.43 & 0.59 & 1.81 & $15.87^{* *}$ \\
Neighbors (N) & 1 & 54.6 & $22.45^{* * *}$ & 1.63 & $14.26^{* *}$ \\
$\mathrm{~S} \times \mathrm{E}$ & 2 & 0.51 & 0.10 & 1.90 & $8.31^{* *}$ \\
$\mathrm{~S} \times \mathrm{P}$ & 2 & 0.25 & 0.05 & 0.42 & 1.84 \\
$\mathrm{~S} \times \mathrm{N}$ & 2 & 9.48 & 1.95 & 0.91 & $4.00^{*}$ \\
$\mathrm{E} \times \mathrm{P}$ & 1 & 0.88 & 0.36 & 0.02 & 0.16 \\
$\mathrm{E} \times \mathrm{N}$ & 1 & 6.85 & 2.82 & 0.14 & 1.21 \\
$\mathrm{P} \times \mathrm{N}$ & 1 & 5.52 & 2.27 & 0.25 & 2.19 \\
$\mathrm{~S} \times \mathrm{E} \times \mathrm{P}$ & 2 & 0.90 & 0.19 & 0.59 & $2.60^{0.09}$ \\
$\mathrm{~S} \times \mathrm{E} \times \mathrm{N}$ & 2 & 1.69 & 0.35 & 0.70 & $3.06^{0.06}$ \\
$\mathrm{~S} \times \mathrm{P} \times \mathrm{N}$ & 2 & 3.70 & 0.76 & 0.66 & $2.89^{0.07}$ \\
$\mathrm{E} \times \mathrm{P} \times \mathrm{N}$ & 1 & 0.22 & 0.09 & 0.02 & 0.16 \\
$\mathrm{~S} \times \mathrm{E} \times \mathrm{P} \times \mathrm{N}$ & 2 & 14.2 & 2.92 & 0.57 & $2.48^{0.10}$ \\
Residual & 35,36 & 85.1 & & 4.11 & \\
& & & & & \\
\hline
\end{tabular}

$2 \mathrm{mo}$ at wave-protected sites and just $7.2 \mathrm{~mm}$ at waveexposed sites $(\mathrm{SE}=1.3)$. Biologically, this difference is large, but statistical significance was hampered by small sample size because, in this split-plot design, each level of wave exposure was replicated by just 3 sites. 


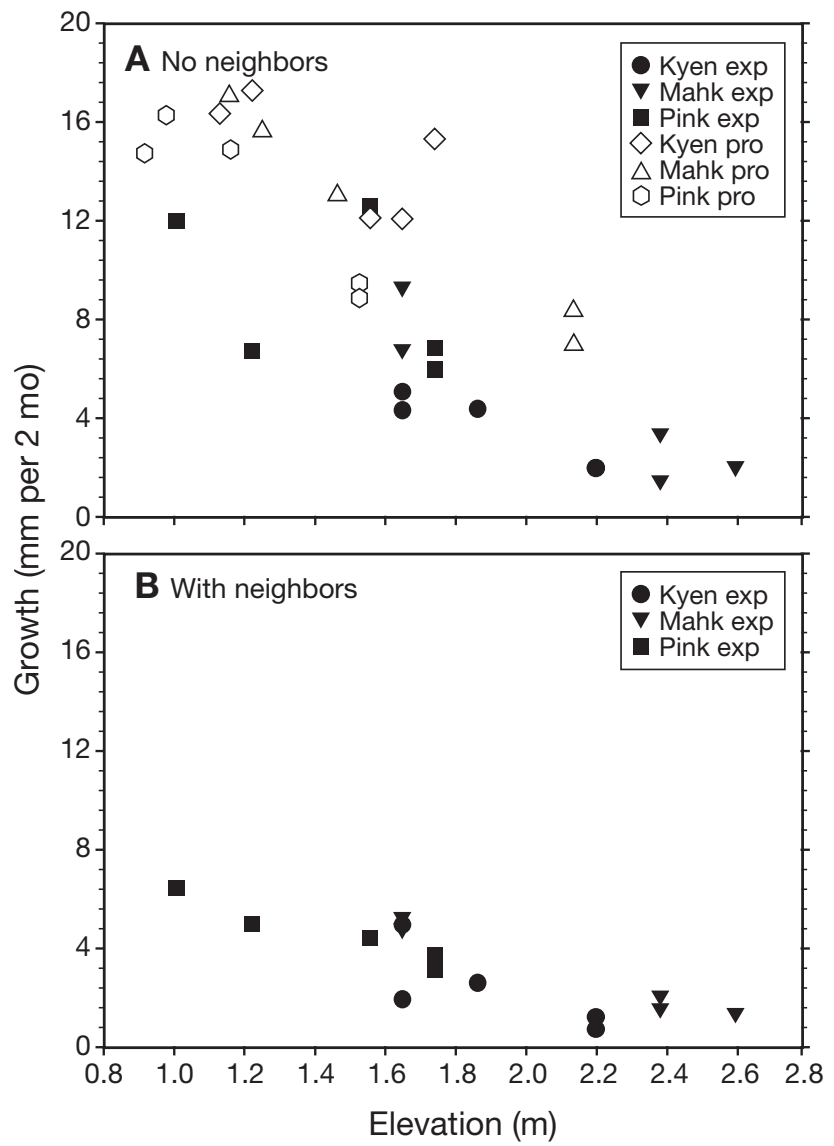

Fig. 1. Crassostrea gigas. Growth (linear shell extension) of $\sim 1 \mathrm{~cm}$ juveniles across tidal elevations at 6 sites in Barkley Sound. Exp: wave-exposed; pro: wave-protected; Pink: Pinkerton. (A) Neighboring organisms removed around transplanted oysters (average of caged $[-\mathrm{P}]$ and uncaged $[+\mathrm{P}]$ treatments). (B) Neighboring organisms present in treatments at wave-exposed sites only (average of $-\mathrm{P}$ and $+\mathrm{P}$ treatments)

\section{Abiotic and biotic effects on oyster survival}

Experimental results on oyster survival $(\ln (x+0.05)$ transformed) demonstrated many significant or marginally significant interactions among factors (Tables 2 \& 3). Turning first to the analysis without neighbors, a significant 3 -way interaction (site[waves] $\times$ elevation $\times$ predators; Table 2) indicated that (at some sites) predators reduced oyster survival more at low than at high tidal elevations. This conclusion emerges from post hoc site-specific regressions of exponential mortality rate across elevation. In the presence of predators, survival improved with elevation at 3 sites (positive slopes at Mahk exposed, Kyen protected, Pinkerton protected, all $\mathrm{p}<0.05$; Fig. 2A), and these positive relationships disappeared when predators were reduced (Fig. 2B). At 2 sites (Kyen exposed, Mahk protected), survival was high ( $>50 \%$ per $2 \mathrm{mo}$ ) regardless of predator treatment (paired $t$-tests: $\mathrm{p}>0.1$ ). Finally, caging did not

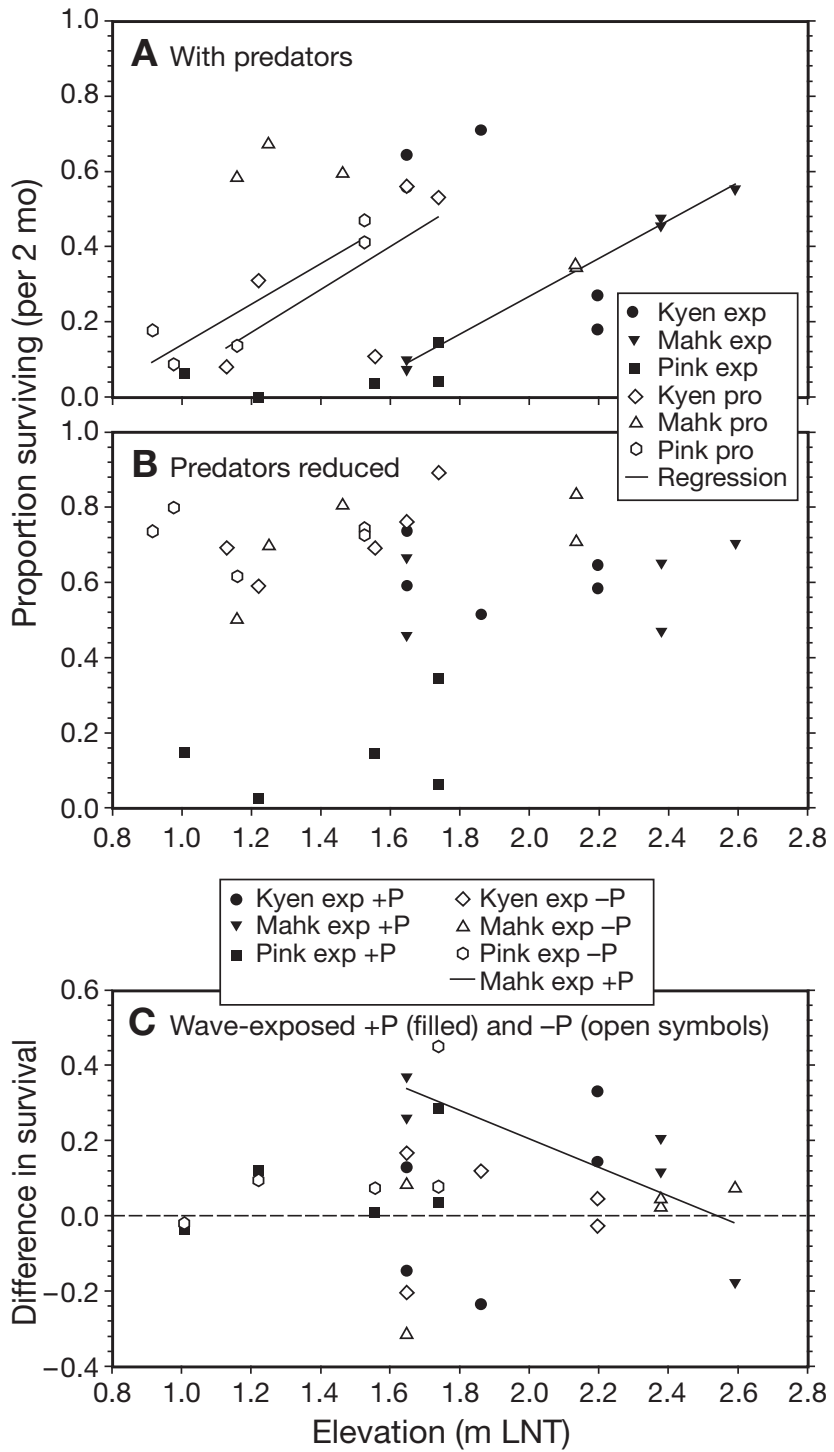

Fig. 2. Crassostrea gigas. Survival (proportion surviving per $2 \mathrm{mo}$ ) of $\sim 1 \mathrm{~cm}$ juveniles across tidal elevations at 6 sites in Barkley Sound. Exp: wave-exposed; pro: wave-protected; Pink: Pinkerton; LNT: lowest normal tide. (A) Predators present at ambient densities, no neighbors. Regression lines are included for sites with significant slopes on $\ln (x+0.05)$-transformed data. (B) Predators reduced with cage exclosures, no neighbors. No sites had significant slopes. (C) Difference in 2 mo survival with $(+\mathrm{N})$ and without neighbors $(-\mathrm{N})$ at waveexposed sites. This difference was calculated separately for caged $(-\mathrm{P})$ and uncaged $(+\mathrm{P})$ treatments. Positive values indicate higher survival with than without neighbors. 'Mahk with predators' showed a significant slope for $\ln (x+0.05)$ transformed data

fully protect oysters at Kyen exposed, where 2 mo survival remained relatively low $(14 \%)$ even though it improved from uncaged conditions $(6 \%$; paired $t$-test: $p=0.008$ ). In contrast to elevation, wave exposure had no significant main or interactive effects on survival (Table 2), and, although survival tended to be higher 
under wave-protected ( $57 \%$ per 2 mo) versus exposed (26\% per 2 mo) conditions, relatively high among-site variation (CV 0.9) precluded statistical significance particularly given low site-level replication.

A similar analysis of oyster survival at wave-exposed sites, including neighbor treatments, revealed a marginally significant 4 -way interaction (Table 3 ; site $\times$ elevation $\times$ predators $\times$ neighbors, $p=0.10$ ), and several 3- and 2-way interactions were also significant, or marginally so (Table 3). As a post hoc test, I examined the effects of neighbors at each wave-exposed site separately. First, to assess protection from predation, I calculated the difference in exponential mortality rates between $+\mathrm{P}+\mathrm{N}$ and $+\mathrm{P}-\mathrm{N}$ treatments on a per block basis. Then, to assess protection from other mortality sources, I calculated the difference in exponential mortality rates between $-\mathrm{P}+\mathrm{N}$ and $-\mathrm{P}-\mathrm{N}$ treatments on a per block basis. Finally, I regressed these differences against tidal elevation. A statistically significant slope appeared in one case, when predators were present at Mahk $(\ln (x+0.05)=-1.5+3.6$ (elevation, $\mathrm{m}), \mathrm{p}=$ $0.009)$, indicating that neighbors protected oysters from mortality by predators at low tidal elevations there (Fig. 2C). Consistent with the previous analysis of treatments without neighbors, post hoc analyses showed no significant predator effect at Kyen exposed (paired $t$-test: $\mathrm{p}=0.12$ ); there was also no effect of neighbors (paired $t$-test: $\mathrm{p}=0.36$ ). At the third waveexposed site (Pinkerton), caging improved 2 mo survival from 14 to $28 \%$ (paired $t$-test: $p=0.02$ ), whereas the removal of neighbors tended to reduce oyster survival (from 33 to $11 \%$; paired $t$-test: $\mathrm{p}=0.08$ ).

\section{DISCUSSION}

This study examined the effects of 2 trophic guilds of native species on invasive oysters (Crassostrea gigas) across ranges of wave exposure and tidal elevation. I focused on the first several months after recruitment because small oysters are particularly vulnerable to mortality but grow rapidly, thus providing a sensitive indicator of spatial variation in performance. In addition, the invader's impact in terms of its representation in the sessile community should increase with early growth and survival, although the eventual cover must also depend on initial recruitment and the extent to which oysters reach a 'size escape' from predation (e.g. Connell 1961, Petraitis 1995).

\section{Abiotic vs. biotic effects on oyster proliferation}

Crassostrea gigas was more abundant at waveprotected than wave-exposed sites (Table 1) and occu- pied a vertical range of 1 to $2.5 \mathrm{~m}$ LNT within an approximately $4 \mathrm{~m}$ tidal amplitude (J. L. Ruesink pers. obs.). Does this distribution arise from spatial variation in abiotic conditions or in biotic interactions (contextdependent interaction strength)? The intertidal distribution of oysters is consistent with limitation by biotic factors. Predation was particularly strong at lower tidal elevations at 3 of 6 sites (Fig. 2A). At a fourth site (Pinkerton exposed), predation also reduced survival (Fig. 2A,B) but showed no interaction with tidal elevation, possibly because all blocks were below $1.8 \mathrm{~m}$ LNT. The proliferation of introduced oysters at midintertidal levels on rocky shores mirrors patterns for some native bivalves that suffer predation at the low intertidal (Robles \& Desharnais 2002). My data indicate that the upper intertidal limit reflects food limitation, as shown by negligible growth (Fig. 1A), as opposed to physical stress (high-intertidal survival was generally high; Fig. 2A). Statistically, this phenomenon appeared as a significant relationship between oyster growth and tidal elevation, which could be considered an abiotic factor (water only covers these oysters for short periods) or a biotic factor (food is in short supply). Regardless, effects of immersion time on bivalve growth are widely documented (Peterson \& Black 1987, Ren \& Ross 2001, Ruesink et al. 2003).

The difference in oyster abundance at waveexposed and protected sites is not clearly related to either abiotic or biotic causes, although tests for effects of wave exposure were much weaker than for other factors because of the split-plot design. Oysters grew slower at wave-exposed (7.2 $\mathrm{mm}$ per $2 \mathrm{mo}$ ) than at protected sites (11.4 mm per $2 \mathrm{mo}$ ), and a possible mechanism is inhibition of feeding at high water flow (Grizzle et al. 1992). However, faster growth at wave-protected sites influences density only indirectly, if oysters reach a size escape from mortality sources earlier. On average, 2 mo survival was also lower at wave-exposed $(26 \%)$ than at protected sites $(57 \%)$, but the difference in oyster density (at least 75-fold; Table 1) exceeded what would be expected from survival differences, even if they were statistically significant. Finally, context-dependent interaction strength cannot account for differences in oyster densities across wave exposure: ANCOVA for oyster survival revealed no predator $\times$ wave exposure interaction. Instead, the contextdependent aspect of predation appeared among sites: regardless of wave exposure, predators reduced oyster survival at most but not all sites, probably due to natural variation in predator densities (e.g. Table 1), as well as discrepancies in the placement of blocks across tidal elevation. I did not test explicitly for effects of neighbors at wave-protected sites, but neighbors are unlikely to be responsible for variable oyster densities across wave exposure. Experimental treatments re- 
vealed strong protective effects of neighbors at some wave-exposed sites (Table 3 ; Fig. 2C), but this facilitation would have to be much stronger at waveprotected sites to account for higher oyster densities there. Rather, I expect a weak interaction between oysters and neighbors where substantial free space is available (wave-protected; Table 1).

Because post-recruitment performance did not explain differences in oyster densities across wave exposure, the key factor is possibly recruitment. In fact, I observed fewer new recruits of Crassostrea gigas at wave-exposed (4 ind. within experimental plots) versus wave-protected sites (50 ind. within experimental plots). A separate study would be necessary to separate abiotic and biotic impacts on recruitment: for instance, recruitment may be lower due to physical properties of waves, or because more filter feeders preempt space or consume larvae. As an example, assembled fouling communities show an inverse relationship between native diversity and invasion because species compensate seasonally, leaving less bare space for settlement (Stachowicz et al. 1999).

\section{Biotic resistance and facilitation}

Predators generally reduced oyster survival over the range of wave exposure (Fig. 2A,B). The identity of predators is uncertain because the experiment was not designed to separate effects within the predator guild. However, surveys of predators indicate that different species and predator densities occupy wave-exposed and wave-protected habitats (Table 1). Seastars and whelks were common at wave-exposed sites (Table 1), but whelks probably contributed little to mortality because drilled shells were rare $(<3 \%$ of $>100$ intact shells [of $\sim 2000$ dead]). Crabs were never present in quantitative samples taken at low tides, but I saw them underwater at wave-protected sites, and mortality at these sites often included chipped shells (J. L. Ruesink pers. obs.). Both seastars and crabs are known to consume oysters in aquaculture (Quayle 1964, BehrensYamada et al. 1993). At 2 sites, predators had no effect on oyster survival, and other observations suggest predation pressure was low: at Kyen exposed, seastars were relatively uncommon, and at Mahk protected, oyster densities were relatively high (Table 1).

Neighbors reduced growth by $44 \%$ (Fig. 1A vs. 1B). The mechanism that slows growth when neighbors surround oysters is unknown. However, large mussels, which dominated space at wave-exposed sites (Table 1), may reduce the food available for newlysettled oysters, much as tall bryozoa pre-empt food from shorter taxa (Buss \& Jackson 1981). Thus, my data represent indirect evidence of food limitation in marine filter feeders on a rocky shore. The absence of any predator effect on growth indicates that cages were not interfering with food delivery. Nevertheless, the lack of cage controls prevents the testing of the possibility that cages mitigated some physical factor impinging on survival, rather than simply altering access by predators.

Although neighbors reduced growth, they also improved survival at some wave-exposed sites. Neighbors appeared to protect oysters from predation at low tidal elevations at Mahk exposed (Fig. 2C). At Pinkerton exposed, neighbors improved 2 mo survival from 11 to $33 \%$ across all treatments, not simply outside cages. These results can be interpreted as neighbors providing protection from factors other than predation, for example, physical stress. However, I believe that predator reduction by caging was particularly ineffective at this site-several small seastars had entered cages at each 2 wk check, and survival of oysters inside cages was relatively low (Fig. 2B) - and that neighbors provided protection from predation both inside and outside cages. These opposing effects of native species on multiple life-history parameters of an invader (i.e. reducing growth but improving survival) may occur more generally within sessile organisms because of competition for resources but protection from physical or biological disturbance (Peterson \& Black 1993). Indeed, facilitation of invaders by other nonindigenous species has been widely recognized (Simberloff \& von Holle 1999, Richardson et al. 2000), and facilitation by natives could be equally common (Maron \& Connors 1996).

\section{Risk of invader proliferation on rocky shores}

Wave-exposed rocky shorelines have sustained relatively few invasions (Wasson et al. 2005). Several possible explanations include poor habitat, strong biological interactions, or lack of propagule pressure (Ruiz et al. 1997). Habitat may be poor if marine species tend to be transported from soft-sediment or fouling communities. Biological interactions may limit invaders because rocky-shore assemblages are known to contain strongly interacting species (Paine 1966). Finally, propagule pressure is likely related to shipping traffic (Ruiz et al. 2000), and ports are not located on shores with big waves. Nevertheless, a few notable species have invaded primary space on rocky shores, namely the mussel Mytilus galloprovincialis and the solitary ascidian Pyura praeputialis. Experimental work has revealed how these invaders interact with native species. For instance, $P$. praeputialis outcompetes native mussels in Chile (Castilla et al. 2004). Its lower limit is set by native predators (Castilla et al. 2004), much as in 
the case of Crassostrea gigas. Similarly, M. galloprovincialis ultimately encroaches on sessile limpets in South Africa, and the limpets hinder but cannot prevent the mussel from occupying space (Steffani \& Branch 2005). C. gigas has been widely introduced (66 countries) and has established breeding populations (at least 17 countries; Ruesink et al. 2005). However, it is not generally reported to invade rocky shorelines, although it can colonize hard substrates or outcrops within bays (Escapa et al. 2004, Robinson et al. 2005). The low cover $(<10 \%)$ of oysters throughout the wave exposure range studied in Barkley Sound (Table 1) may reflect the unsuitability of this habitat.

Many risk assessments for introduced species emphasize both the autecology of the invader (habitat match) and the possibility of biotic resistance by species that are already present (Ruesink et al. 1995). Given context-dependence of species interactions, however, biotic resistance itself may vary across habitats or even sites within habitats. Based on this study, the dramatic differences in oyster density across sites are consistent with an abiotic mechanism that limits proliferation, specifically wave exposure. However, at both low and high wave exposure, the removal of native predators tended to improve the oyster's chance of reaching high abundance through better survival. Invasion risk, as indicated by oyster performance, was particularly high at intermediate tidal elevations: above this level, oysters grew slowly, and below this level, mortality could be quite high (Figs. 1 \& 2). In their review of plant invasions, Levine et al. (2004) stress that biotic resistance influences density but not range (presence) of non-native species. The results for oysters are consistent with this review at larger scales (across wave exposure) but not smaller scales (across tidal elevation).

Invasion biology is just beginning to address possible interactive effects of multiple resident species on invaders (Callaway et al. 1999, Law et al. 2000). In the present study, simultaneous manipulation of neighbors and predators at wave-exposed sites suggests that their effects on oysters are often additive: statistically significant neighbor $\times$ predator effects occurred only at 1 of 3 sites (Fig. 2C). However, these 2 guilds of species affected oysters quite differently. Guild-specific effects should be expected for different trophic levels, and indeed, predators reduced oyster survival, whereas competitors improved survival and reduced growth. Nevertheless, much of the discussion of biotic resistance fails to distinguish how different species contribute to keeping invaders rare (Levine \& D'Antonio 1999). There is an obvious need for additional studies that reduce diversity of intact systems, both at random and to test particular mechanisms, to examine how dynamics of non-native invaders change. Such studies will help to focus concerns about invaders on areas where natural abiotic or biotic resistance is lacking.

Acknowledgements. The Centre for Biodiversity Research at the University of British Columbia, Alberni Marine Transport, and the ARCS Foundation supported this study. I am grateful to the Tseshaht Band and the Province of British Columbia for permission to work in Barkley Sound. Many thanks to E. Buhle, P. Leavitt, J. Maron, R. T. Paine, M. Scheuerell, D. Schindler, and A. Trimble for insightful reviews. The manuscript was substantially improved by comments from 2 anonymous reviewers and C. H. Peterson.

\section{LITERATURE CITED}

Behrens Yamada S, Metcalf H, Baldwin BC (1993) Predation by the crab, Cancer oregonensis Dana, inside oyster trays. J Shellfish Res 12:89-92

Bishop MJ, Peterson CH (2006) When r-selection may not predict introduced-species proliferation: predation of a nonnative oyster. Ecol Appl 16:718-730

Bourne N (1979) Pacific oysters, Crassostrea gigas Thunberg, in British Columbia and the South Pacific Islands. In: Mann R (ed) Exotic species in mariculture. MIT Press, Cambridge, MA, p 1-51

Burdon JJ (1987) Diseases and plant population biology. Cambridge University Press, Cambridge

Buss LW, Jackson JBC (1981) Planktonic food availability and suspension-feeder abundance: evidence of in situ depletion. J Exp Mar Biol Ecol 49:151-161

Callaway R, DeLuca T, Belliveau W (1999) Biological-control herbivores may increase competitive ability of the noxious weed Centaurea maculosa. Ecology 80:1196-1201

Castilla JC, Guinez R, Caro AU, Ortiz V (2004) Invasion of a rocky intertidal shore by the tunicate Pyura praeputialis in the Bay of Antofagasta, Chile. Proc Nat Acad Sci USA 101:8517-8524

Chapin FS, Sala OE, Burke IC, Grime JP and 10 others (1998) Ecosystem consequences of changing biodiversity. BioScience 48:45-52

Connell JH (1961) The influence of interspecific competition and other factors on the distribution of the barnacle Chthamalus stellatus. Ecol 42:710-723

Crawley MJ (1986) The population biology of invaders. Philos Trans R Soc London B 314:711-731

Elton CS (1958) The ecology of invasions by animals and plants. Chapman \& Hall, London

Escapa M, Isacch JP, Daleo P, Alberti J and 6 others (2004) The distribution and ecological effects of the introduced Pacific oyster Crassostrea gigas (Thunberg, 1793) in northern Patagonia. J Shellfish Res 23:765-772

Goergen E, Daehler CC (2001) Reproductive ecology of a native Hawaiian grass (Heteropogon contortus; Poaceae) versus its invasive alien competitor (Pennisetum setaceum; Poaceae). Int J Plant Sci 162:317-326

Grizzle RE, Langan R, Howell WH (1992) Growth responses of suspension-feeding bivalve mollusks to changes in water flow: differences between siphonate and nonsiphonate taxa. J Exp Mar Biol Ecol 162:213-228

His E, Robert R, Dinet A (1989) Combined effects of temperature and salinity on fed and starved larvae of the Mediterranean mussel Mytilus galloprovincialis and the Japanese oyster Crassostrea gigas. Mar Biol 100:455-463

Jensen GC, McDonald PS, Armstrong DA (2002) East meets west: competitive interactions between green crab Carci- 
nus maenas, and native and introduced shore crab Hemigrapsus spp. Mar Ecol Prog Ser 225:251-262

Law R, Weatherby AJ, Warren PH (2000) On the invasibility of persistent protist communities. Oikos 88:319-326

Levine JM (2000) Species diversity and biological invasions: relating local process to community pattern. Science 288 : 852-854

Levine JM, D'Antonio CM (1999) Elton revisited: a review of evidence linking diversity and invasibility. Oikos 87:15-26

Levine JM, Adler PB, Yelenik SG (2004) A meta-analysis of biotic resistance to exotic plant invasions. Ecology Letters 7:975-989

Lodge DM (1993) Biological invasions: lessons for ecology. Trends Ecol Evol 8:133-137

Mack RN (1996) Predicting the identity and fate of plant invaders: emergent and emerging approaches. Biol Conserv 78:107-121

Maron JL, Connors PG (1996) A native nitrogen-fixing shrub facilitates weed invasion. Oecologia 105:302-312

OTA (Office of Technology Assessment ) (1993) Harmful nonindigenous species in the United States. U.S. Government, Washington, DC

Paine RT (1966) Food web complexity and species diversity. Am Nat 100:65-75

Parker IM, Simberloff D, Lonsdale WM, Goodell K, and 7 others (1999) Impact: toward a framework for understanding the ecological effects of invaders. Biol Invasions 1:3-19

Peterson AT, Vieglais DA (2001) Predicting species invasions using ecological niche modeling: new approaches from bioinformatics attack a pressing problem. BioScience 51: 363-371

Peterson CH, Black R (1987) Resource depletion by active suspension feeders on tidal flats: influence of local density and tidal elevation. Limnol Oceanogr 32:143-166

Peterson CH, Black R (1993) Experimental tests of the advantages and disadvantages of high density for two coexisting cockles in at Southern Ocean lagoon. J Anim Ecol 62: 614-633

Petraitis PS (1995) The role of growth in maintaining spatial dominance by mussels (Mytilus edulis). Ecology 76: 1337-1346

Pimentel D, Lach L, Zuniga R, Morrison D (2000) Environmental and economic costs of nonindigenous species in the United States. BioScience 50:53-65

Quayle DB (1964) Distribution of introduced marine mollusca in British Columbia waters. J Fish Res Board Can 21: 1155-1181

Rejmanek M (1989) Invasibility of plant communities. In: Drake JA, Mooney HA, di Castri F, Groves RH, Kruger FJ, Rejmanek M, Williamson M (eds) Biological invasions: a global perspective. Wiley, Chichester, p 369-388

Ren JS, Ross AH (2001) A dynamic energy budget model of the Pacific oyster Crassostrea gigas. Ecol Model 142: 105-120

Reusch TBH (1998) Native predators contribute to invasion resistance to the non-indigenous bivalve Musculista

Editorial responsibility: Charles Peterson (Contributing Editor), Morehead City, North Carolina, USA senhousia in southern California, USA. Mar Ecol Prog Ser 170:159-168

Richardson DM, Allsopp J, D'Antonio CM, Milton SJ, Rejmanek M (2000) Plant invasions - the role of mutualisms. Biol Rev Camb Philos Soc 75:65-93

Robinson JV, Wellborn GA (1988) Ecological resistance to the invasion of a fresh-water clam, Corbicula fluminea: fish predation effects. Oecologia 77:445-452

Robinson TB, Griffiths CL, Tonin A, Bloomer P, Hare MP (2005) Naturalized populations of oysters, Crassostrea gigas along the South African coast: distribution, abundance and population structure. J Shellfish Res 24:443-450

Robles C, Desharnais R (2002) History and current development of a paradigm of predation in rocky intertidal communities. Ecology 83:1521-1536

Ruesink JL, Parker IM, Groom MJ, Kareiva PM (1995) Reducing the risks of nonindigenous species introductions: guilty until proven innocent. BioScience 45:465-477

Ruesink JL, Roegner GC, Dumbauld BR, Newton JA, Armstrong DA (2003) Contributions of oceanic and watershed energy sources to secondary production in a northeastern Pacific estuary. Estuaries 26:1079-1093

Ruesink JL, Lenihan HS, Trimble AC, Heiman KW, Micheli F, Byers JE, Kay M (2005) Introduction of non-native oysters: ecosystem effects and restoration implications. Annu Rev Ecol Evol Syst 36:643-689

Ruiz GM, Carlton JT, Grosholz ED, Hines AH (1997) Global invasions of marine and estuarine habitats by nonindigenous species: mechanisms, extent, and consequences. Am Zool 37:621-632

Ruiz GM, Fofonoff PW, Carlton JT, Wonham MJ, Hines AH (2000) Invasion of coastal marine communities in North America: apparent patterns, processes, and biases. Annu Rev Ecol Syst 31:481-531

Shea K, Chesson P (2002) Community ecology theory as a framework for biological invasions. Trends Ecol Evol 17:170-176

Simberloff D, Von Holle B (1999) Positive interactions of nonindigenous species: invasional meltdown? Biol Invasions $1: 21-32$

Soluk DA (1993) Multiple predator effects: predicting combined functional response of stream fish and invertebrate predators. Ecology 74:219-225

Stachowicz JJ, Whitlach RB, Osman RW (1999) Species diversity and invasion resistance in a marine ecosystem. Science 286:1577-1579

Steffani CN, Branch GM (2005) Mechanisms and consequences of competition between an alien mussel, Mytilus galloprovincialis, and an indigenous limpet, Scutellastra argenvillei. J Exp Mar Biol Ecol 317:127-142

Wasson K, Fenn K, Pearse JS (2005) Habitat differences in marine invasions of central California. Biol Invasions 7: 935-948

Wootton JT (1994) Predicting direct and indirect effects: an integrated approach using experiments and path analysis. Ecology 75:151-165

Submitted: March 4, 2004; Accepted: December 29, 2006

Proofs received from author(s): January 17, 2007 